\title{
ADAPTACIÓN DEL “MARCO COMÚN DE COMPETENCIA DIGITAL DOCENTE” AL ÁREA DE EDUCACIÓN MUSICAL
}

\section{Recepción: 09/09/2019 | Revisión: 09/10/2019 | Aceptación: 06/12/2019}

\section{Diego CALDERÓN-GARRIDO}

Universidad Internacional de La Rioja

dcalderongarrido@gmail.com

\author{
Xavier CARRERA FARRAN \\ Universitat de Lleida \\ carrera@pip.udl.cat
}

\begin{abstract}
Resumen: En el año 2017 el Instituto Nacional de Tecnologías Educativas y de Formación del Profesorado (INTEF) propuso el "Marco Común de Competencia Digital Docente", compuesto por cinco áreas y entre tres y seis competencias en cada una de ellas, como referente de la Competencia Digital Docente (CDD) del profesorado. En este artículo se hace una adaptación de cada área y competencia definidas por el INTEF al ámbito de la Educación Musical. Esta adaptación facilita al profesorado la autoevaluación de la propia CDD, además de ser un referente para la definición de acciones de formación continua e inicial del docente de Música.
\end{abstract}

Palabras clave: competencia digital docente; "Marco Común de Competencia Digital Docente”; INTEF; Educación Musical; tecnología digital.

\section{ADAPTATION OFTHE "COMMON FRAMEWORK OF DIGITAL TEACHING COMPETENCE"TOTHE AREA OF MUSIC EDUCATION}

Abstract: In 2017, the National Institute of Educational Technologies and Teacher Training (INTEF) proposed the "Common Framework of Digital Teaching Competence", composed of five areas and between three and six competencies in each of them, as a benchmark of the Digital Teaching Competence (DTC). This paper makes an adaptation of each area and competence defined by the INTEF to the field of music education. This adaptation makes it easier for teachers to self-evaluate the DTC itself as well as being a reference for the definition of continuous and initial training actions for the Music teacher.

Keywords: digital teaching competence; "Common Framework of Digital Teaching Competence"; INTEF; music teaching; digital technology.

\section{ADAPTACIÓ DEL "MARC COMÚ DE COMPETĖNCIA DIGITAL DOCENT" A L'ÀREA D'EDUCACIÓ MUSICAL}

Resum: L'any 2017 l'Institut Nacional de Tecnologies Educatives i de Formació del Professorat (INTEF) va proposar el "Marc Comú de Competència Digital Docent", que consta de cinc àrees i entre tres i sis competències en cada una delles, com referent de la Competència Digital Docent (CDD) del professorat. En aquest article es fa una adaptació de cada àrea $i$ competència definides per l'INTEF en làmbit de l'Educació Musical. Aquesta adaptació facilita al professorat lautoavaluació de la seva CDD a més de ser un referent per a la definició d'accions de formació contínua i inicial del docent de Música.

Paraules clau: competència digital docent; "Marc Comú de Competència Digital Docent"; INTEF; Educació Musical; tecnologia digital. 


\section{Introducción}

Ya no hace falta justificar el uso de la tecnología digital basándose en los avances de la sociedad actual. Atrás quedaron los tiempos en los que se repetían los pros y contras sobre su utilización mostrándose las luces y sombras. Ahora simplemente se trata de cómo usarla. Cómo gestionar las relaciones humanas mediadas por las nuevas situaciones que se van produciendo.

En este adaptación, como no podía ser de otra forma, el proceso de enseñanza-aprendizaje se ha visto afectado. Se han ocasionado tensiones en las cuáles el profesorado se ha visto involucrado y, en ocasiones, sobrepasado por una sociedad inserta en "un mundo volátil como el de la modernidad líquida, en el cual casi ninguna estructura conserva su forma el tiempo suficiente como para garantizar alguna confianza y cristalizarse en una responsabilidad a largo plazo" (Bauman, 2005: 36). Así pues, nos adentramos en un proceso en el que, tal como afirma la comisión europea en su informe Education and Training Monitor (2016) se trata de invertir esfuerzos que mejoren la calidad de las competencias que son necesarias en la sociedad actual, pero siempre mirando al futuro.

En este sentido, la competencia digital, entendida como una de las competencias docentes que forman parte del perfil del profesorado, contempla componentes de alfabetización y capacitación digital acordes con el nivel, ámbito y especialización del profesorado (Carrera y Coiduras, 2012). Así pues, en el área de la educación musical se podrían establecer diferentes parámetros en función de cada caso, considerando así las diferencias existentes entre las escuelas de música, los conservatorios superiores, la formación inicial de maestros de música o el maestro de primaria, por poner solo algunos ejemplos (Calderón-Garrido, 2013). A pesar de esta diversidad, la competencia digital docente se considera transversal a todos y cada uno de los ámbitos por el aporte significativo que representa (Belletich, Angel-Alvarado y Wilhelmi, 2017).

En este artículo se establece un marco competencial digital docente adaptado al ámbito de la educación musical partiendo de la propuesta realizada por el Instituto Nacional de Tecnologías Educativas y Formación del Profesorado (INTEF, 2017).

\section{La competencia digital docente}

Ya en el 2006 la Comisión Europea señaló la competencia digital como una competencia clave:

La competencia digital implica el uso crítico y seguro de las Tecnologías de la Sociedad de la Información para el trabajo, el tiempo libre y la comunicación. Apoyándose en habilidades TIC básicas: uso de ordenadores para recuperar, evaluar, almacenar, producir, presentar e intercambiar información, y para comunicar y participar en redes de colaboración a través de Internet (Parlamento Europeo y del Consejo, 2006: 15).

Posteriormente, el informe DIGICOMP (Digital Competence) la consideró una competencia transversal que, como tal, permitiría adquirir otras. De la misma forma la relacionó con muchas de las habilidades que los ciudadanos deberían adquirir para asegurar la participación activa en la sociedad y la economía del siglo XXI (Ferrari, 2013). Este informe tuvo su versión centrada en la educación, en la que se hacía hincapié en la necesidad de incluir la competencia digital en 
dicho ámbito educativo DiGiCompEdu, 2017).

En el ámbito educativo, tal como describían Tourón, Martín, Navarro y Iñigo (2018), la tecnología digital podría aportar inmediatez a la hora de acceder a la información, generación de conocimiento y recursos, la evaluación continua que permitiese rediseñar itinerarios curriculares, colaboración entre compañeros dentro y fuera del aula, etc. Así pues, la competencia digital, vista desde el papel del docente, debería basarse no en el simple uso de la tecnología, sino en la mediación entre esta y el alumnado, asegurando una interacción efectiva incorporando y utilizando adecuadamente la tecnología de la información y la comunicación (TIC) como recurso metodológico dentro del proceso de enseñanza-aprendizaje (Fullan y Donelly, 2013). Por tanto, se puede definir la Competencia Digital Docente como una conjunción de la competencia instrumental digital y la competencia metodológica digital, a través de la cual se facilita al alumnado la adquisición de su propia competencia digital, se fomentan procesos que mejoren el acto educativo acorde con la actual era digital, y contribuye al propio desarrollo profesional en función a los cambios que se están produciendo en la sociedad y la propia escuela (Generalitat de Catalunya, 2018).

Tal es su importancia que todos los países vienen realizando un esfuerzo que se materializa en diversas acciones a través de formación y difusión de buenas prácticas. En el caso de España, y amparado por la UNESCO (2002), en el año 2012 nació el proyecto de "Marco Común de Competencia Digital Docente", publicando, tras varios borradores, su propuesta final en el año 2017. En él se busca que el docente tome conciencia de su propia competencia digital. En esta propuesta se establecen cinco áreas competenciales, tal como se muestra en la Figura 1:

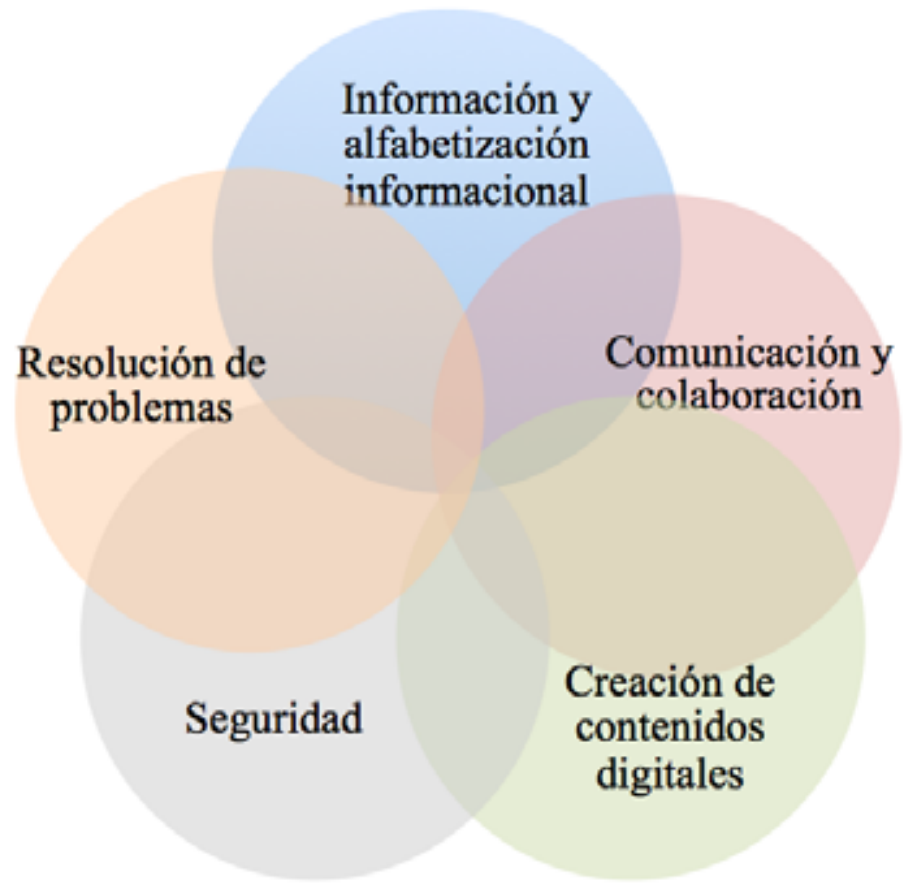

Figura 1. Áreas del Marco Común de Competencia Digital Docente. Fuente propia adaptada de INTEF (2017). 
Para cada una de las cinco áreas se han identificado entre 3 y 6 competencias relacionadas, además de tres niveles $(\mathrm{A}=\mathrm{Básico}$; $\mathrm{B}=$ Intermedio; $\mathrm{C}=$ Avanzado) desarrollados que permitirían conocer a cada docente su nivel competencial.

\section{Adaptación del “Marco Común de Competencia Digital Do- cente" (INTEF, 2017) al ámbito de la educación musical}

Así pues, si se parte de la propuesta del "Marco Común de Competencia Digital Docente" (INTEF, 2017), se pueden reformular cada descriptor de cada una de las áreas, precisando y contextualizando las competencias y los contenidos de la rúbrica en cada uno de los indicadores que la configuran, adecuándolo así a las especificidades de la Didáctica de la Música. Aquí se muestra la adaptación descrita.

Área 1. Información y alfabetización informacional: buscar, identificar, descargar, almacenar, organizar y examinar la información digital relacionada con la educación musical, evaluando su propósito e importancia para las tareas docentes.

Competencia 1. Navegación, búsqueda y filtrado de información, datos y contenidos digitales. Buscar información, datos y contenidos digitales en red relacionados con la educación musical y acceder a ellos; expresar de manera organizada las necesidades de información; encontrar información relevante para el aula de música; seleccionar recursos educativos de forma eficaz en diversos formatos (mp3, midi, etc.); gestionar distintas fuentes de información; crear tácticas personales de información y formación referida a la educación musical a través de recursos en línea.

Competencia 2. Evaluación de información, datos y contenidos digitales. Reunir, procesar, comprender y evaluar información, datos y contenidos digitales propios del área de educación musical de forma crítica y adecuada para la etapa y ámbito en el que desarrolle su docencia (conservatorio, escuela, instituto, universidad, etc.).

Competencia 3. Almacenamiento y recuperación de información, datos y contenidos digitales. Gestionar y almacenar información, datos y contenidos digitales para facilitar su recuperación, organizar información, datos y contenidos digitales propios del área de Educación Musical (partituras digitales, bases musicales, etc.).

Esta área es especialmente significativa en el ámbito de la Educación Musical, ya que en un mundo globalizado en el que el material musical existente en la red es interminable, el saber localizar las audiciones, partituras, bases musicales, etc., que interesan al docente para cada aula, se convierte en crucial. Resulta, además, especialmente útil si se quieren trabajar músicas de otras culturas. 
Competencia 1. Navegación, búsqueda y filtrado de información, datos y contenidos digitales

\begin{tabular}{|c|c|c|}
\hline A- Básico & B - Intermedio & C - Avanzado \\
\hline $\begin{array}{l}\text { Sabe que la red es una fuente de } \\
\text { recursos para la docencia y recurre a } \\
\text { ella para buscar material que pueda } \\
\text { usar en las clases de música. }\end{array}$ & $\begin{array}{l}\text { Sabe navegar por Internet para } \\
\text { localizar información y recursos } \\
\text { educativos digitales en diferentes } \\
\text { formatos de fuentes de información } \\
\text { dinámicas y de interés para su } \\
\text { labor docente. Es capaz de localizar } \\
\text { partituras, archivos midi, mp3, etc. }\end{array}$ & $\begin{array}{l}\text { Sabe usar herramientas de búsqueda } \\
\text { avanzada, así como filtros para } \\
\text { encontrar información y recursos } \\
\text { apropiados a sus necesidades } \\
\text { docentes. Diferencia entre los } \\
\text { diferentes buscadores y sitios web, } \\
\text { y cómo estos pueden proporcionar } \\
\text { o bien partituras, o archivos midi, o } \\
\text { recursos vocales, etc. }\end{array}$ \\
\hline \multicolumn{3}{|c|}{ Competencia 2. Evaluación de información, datos y contenidos digitales } \\
\hline A- Básico & B - Intermedio & C - Avanzado \\
\hline $\begin{array}{l}\text { Sabe que existe mucha información } \\
\text { y recursos docentes en Internet, } \\
\text { pero también que no todo lo que } \\
\text { encuentra es fiable y puede ser } \\
\text { reutilizado en el área de educación } \\
\text { musical. Para ello realiza una } \\
\text { discriminación básica en función del } \\
\text { formato, autor, etc. }\end{array}$ & $\begin{array}{l}\text { Conoce las licencias de uso que } \\
\text { permiten la reutilización o difusión } \\
\text { de los recursos que encuentra en } \\
\text { internet así como las características } \\
\text { y limitaciones de los programas de } \\
\text { música de libre acceso. Evalúa y usa } \\
\text { los más adecuados para su docencia } \\
\text { musical. }\end{array}$ & $\begin{array}{l}\text { Es crítico y selecciona las fuentes } \\
\text { de información, los perfiles de } \\
\text { profesores de música o arreglistas } \\
\text { musicales a los que sigue y las } \\
\text { comunidades relacionadas con la } \\
\text { música a las que pertenece. }\end{array}$ \\
\hline \multicolumn{3}{|c|}{ Competencia 3. Almacenamiento y recuperación de información, datos y contenidos digitales } \\
\hline A- Básico & B - Intermedio & C - Avanzado \\
\hline $\begin{array}{l}\text { Posee competencias básicas para } \\
\text { el almacenamiento de información } \\
\text { digital en su labor docente, } \\
\text { distinguiendo entre archivos mp3, } \\
\text { flac., sib., etc. A pesar de esto es } \\
\text { consciente de que no controla todos } \\
\text { los dispositivos ni posibilidades para } \\
\text { ello. }\end{array}$ & $\begin{array}{l}\text { Sabe etiquetar, guardar, recuperar } \\
\text { y gestionar archivos, contenidos } \\
\text { e información propios del aula de } \\
\text { música y tiene su propia estrategia } \\
\text { de almacenamiento. }\end{array}$ & $\begin{array}{l}\text { Dispone de una estrategia social, } \\
\text { conectado a expertos, músicos, } \\
\text { compañeros y alumnos a través de } \\
\text { medios digitales, combinando el } \\
\text { almacenamiento local con el uso } \\
\text { de la nube usando, además, sitios } \\
\text { web específicos para la educación } \\
\text { musical. }\end{array}$ \\
\hline
\end{tabular}

Tabla 1. Niveles del área 1. Información y alfabetización informacional. Fuente propia adaptada de INTEF (2017).

Área 2. Comunicación y colaboración: comunicar en medios digitales, compartir recursos en línea, conectar y colaborar con otros docentes de música a través de herramientas digitales, interactuar y participar en comunidades y redes específicas del área de la educación musical; conciencia intercultural.

Competencia 1. Interacción mediante las tecnologías digitales. Interaccionar por medio de diversos dispositivos y aplicaciones digitales; entender cómo se distribuye, presenta y gestiona la comunicación digital; comprender el uso adecuado de las distintas formas de comunicación a través de medios digitales; contemplar diferentes formatos de comunicación; adaptar estrategias y modos de comunicación en el área de didáctica de la música.

Competencia 2. Compartir información y contenidos digitales. Compartir la ubicación de la información y de los contenidos digitales encontrados relacionados con la educación musical; estar dispuesto y ser capaz de compartir conocimiento, contenidos y recursos con otros docentes del área.

Competencia 3. Participación ciudadana en línea. Implicarse con la sociedad mediante la participación en línea; buscar oportunidades tecnológicas para el empoderamiento y el autodesarrollo en cuanto a las tecnologías y a los entornos digitales; ser consciente del potencial de la tecnología para la participación ciudadana y, en concreto, para la visibilización del docente de música. 
Competencia 4. Colaboración mediante canales digitales. Utilizar tecnologías y medios para el trabajo entre profesores de música, para los procesos colaborativos y para la creación y construcción común de recursos, conocimientos y contenidos educativo musicales.

Competencia 5. Netiqueta. Estar familiarizado con las normas de conducta en interacciones en línea; estar concienciado en lo referente a la diversidad cultural y estilística en lo que a música se refiere; ser capaz de protegerse a sí mismo y a otros de posibles peligros en línea desarrollando estrategias que permitan identificar conductas inadecuadas.

Competencia 6. Gestión de la identidad digital. Crear, adaptar y gestionar una o varias identidades digitales como docente de música, y ser capaz de proteger la propia reputación digital.

Esta área permite el crecimiento como docente de música a través del trabajo entre iguales. Así se pueden solucionar dudas respecto a propuestas didácticas, inclusión de nuevas músicas y las denominadas músicas del mundo en el aula, ensayos intercentros para actuaciones finales, etc.

Competencia 1. Interacción mediante las tecnologías digitales

\begin{tabular}{|l|l|l|}
\hline A- Básico & B - Intermedio & C - Avanzado \\
\hline $\begin{array}{l}\text { Sabe que la red es una fuente } \\
\text { de recursos, aplicaciones y } \\
\text { plataformas para la comunicación } \\
\text { en general, y de forma particular } \\
\begin{array}{l}\text { con sus colegas docentes de } \\
\text { música, alumnos, familias y, en su } \\
\text { caso, administración educativa, con } \\
\text { quienes interactúa de forma básica. }\end{array}\end{array}$ & $\begin{array}{l}\text { Interactúa y se comunica sin } \\
\text { dificultad tanto de manera } \\
\text { síncrona como asíncrona a } \\
\text { través de varias aplicaciones y } \\
\text { servicios de comunicación digital, } \\
\text { seleccionado el medio más } \\
\text { apropiado para ello. }\end{array}$ & $\begin{array}{l}\text { Usa una amplia gama de aplicaciones y } \\
\text { servicios de interacción y comunicación } \\
\text { digital, de tipología variada, y tiene } \\
\text { de una de las mismas, que adapta } \\
\text { en función de la naturaleza de la } \\
\text { interacción y la comunicación digital } \\
\text { que él o sus interlocutores necesiten } \\
\text { en cada momento. }\end{array}$ \\
\hline
\end{tabular}

Competencia 2. Compartir información y contenidos digitales

\begin{tabular}{|c|c|c|}
\hline A- Básico & B - Intermedio & C - Avanzado \\
\hline $\begin{array}{l}\text { Comparte archivos y contenidos } \\
\text { relacionados con la educación } \\
\text { musical a través de medios } \\
\text { tecnológicos sencillos. }\end{array}$ & $\begin{array}{l}\text { Participa en redes sociales } \\
\text { y comunidades en línea, en } \\
\text { las que transmite o comparte } \\
\text { conocimientos, contenidos e } \\
\text { información relacionados con la } \\
\text { educación musical. }\end{array}$ & $\begin{array}{l}\text { Comparte de forma activa información, } \\
\text { contenidos y recursos relacionados } \\
\text { con la educación musical a través } \\
\text { de comunidades en línea, redes y } \\
\text { plataformas de colaboración. }\end{array}$ \\
\hline \multicolumn{3}{|c|}{ Competencia 3. Participación ciudadana en línea } \\
\hline A- Básico & B - Intermedio & C - Avanzado \\
\hline $\begin{array}{l}\text { Sabe que la tecnología se puede } \\
\text { utilizar para interactuar con } \\
\text { distintos servicios y hace un uso } \\
\text { pasivo de algunos, en el ámbito de } \\
\text { la Educación Musical. }\end{array}$ & $\begin{array}{l}\text { Utiliza activamente algunos } \\
\text { aspectos de nivel medio de los } \\
\text { servicios en línea para su docencia } \\
\text { musical. }\end{array}$ & $\begin{array}{l}\text { Es un usuario habitual y activo en la } \\
\text { comunicación y participación en línea } \\
\text { en cualquier tipo de acción referida a } \\
\text { la Educación Musical desde el punto } \\
\text { de vista social, cultural, político o } \\
\text { administrativo, en distintos foros de } \\
\text { debate virtuales. Transmite y forma en } \\
\text { este aspecto a su alumnado }\end{array}$ \\
\hline
\end{tabular}

Competencia 4. Colaboración mediante canales digitales

\begin{tabular}{|c|c|c|}
\hline A- Básico & B - Intermedio & C - Avanzado \\
\hline $\begin{array}{l}\text { Colabora, de forma muy sencilla, } \\
\text { usando recursos y aplicaciones } \\
\text { digitales que permiten el trabajo } \\
\text { con otros docentes de música, } \\
\text { intercambiando archivos o creando } \\
\text { documentos compartidos tales } \\
\text { como backing tracks o partituras. }\end{array}$ & $\begin{array}{l}\text { Debate y elabora productos } \\
\text { educativos en colaboración con } \\
\text { otros docentes y con su alumnado } \\
\text { de música, utilizando diversos } \\
\text { recursos digitales no muy } \\
\text { complejos }\end{array}$ & $\begin{array}{l}\text { Usa y estimula el uso de diversos } \\
\text { espacios y herramientas digitales de } \\
\text { trabajo colaborativo con sus otros } \\
\text { docentes de música desempeñando } \\
\text { distintas funciones: creación, gestión } \\
\text { y/o participación. }\end{array}$ \\
\hline
\end{tabular}




\begin{tabular}{|c|c|c|}
\hline A- Básico & B - Intermedio & C - Avanzado \\
\hline $\begin{array}{l}\text { Es conocedor de las normas básicas } \\
\text { de acceso y comportamiento y } \\
\text { comunicación en las redes sociales } \\
\text { y canales digitales, así como los } \\
\text { peligros y conductas inadecuadas } \\
\text { que pueden afectar a su alumnado } \\
\text { de música }\end{array}$ & $\begin{array}{l}\text { Es capaz de seguir las normas } \\
\text { de netiqueta en la comunicación } \\
\text { digital mostrándose respetuoso } \\
\text { ante la diversidad cultural y } \\
\text { estilística en el ámbito de la } \\
\text { música. }\end{array}$ & $\begin{array}{l}\text { Emplea diversos aspectos de la } \\
\text { netiqueta a diferentes espacios y } \\
\text { contextos de comunicación digital en } \\
\text { el ámbito de la Educación Musical, } \\
\text { y es capaz de identificar conductas } \\
\text { inadecuadas }\end{array}$ \\
\hline \multicolumn{3}{|c|}{ Competencia 6. Gestión de la identidad digital } \\
\hline A- Básico & B - Intermedio & C - Avanzado \\
\hline $\begin{array}{l}\text { Conoce los beneficios y los riesgos } \\
\text { relacionados con la identidad } \\
\text { digital como docente de música. }\end{array}$ & $\begin{array}{l}\text { Sabe crear su propia identidad } \\
\text { digital y rastrear su propia huella } \\
\text { digital, gestionado los datos } \\
\text { generados como docente de } \\
\text { música. }\end{array}$ & $\begin{array}{l}\text { Gestiona diferentes identidades } \\
\text { digitales, supervisa la información } \\
\text { creada por su interacción y protege su } \\
\text { reputación como docente de música en } \\
\text { función del contexto y de su finalidad. }\end{array}$ \\
\hline
\end{tabular}

Tabla 2. Niveles del área 2. Comunicación y colaboración. Fuente propia adaptada de INTEF (2017).

Área 3. Creación de contenido digital: crear y editar nuevos contenidos y producciones musicales, así como saber aplicar los derechos de propiedad intelectual y las licencias de uso.

Competencia 1. Desarrollo de contenidos digitales. Crear, editar y mejorar contenidos digitales propios y ajenos aplicables al área de educación musical a través de los recursos digitales (partituras, pistas de acompañamiento, etc.).

Competencia 2. Integración y reelaboración de contenidos digitales. Modificar, perfeccionar y combinar los recursos existentes para crear contenido digital y conocimiento nuevo, original y relevante que sea adecuado para el aula de música (backing tracks, arreglos musicales, etc.).

Competencia 3. Derechos de autor y licencias. Entender cómo se aplican los derechos de autor y las licencias a la información y a los contenidos digitales que se usa en el área de Educación Musical.

Competencia 4. Programación. Realizar modificaciones en software, aplicaciones y dispositivos destinados a la educación musical (editores de audio, secuenciadores, etc.).

Cada vez son más los profesores de Música que crean sus propios blogs y páginas web repletos de Kahoots, musicogramas, partituras, etc. El saber usar todo ese material y adecuarlo a los propios intereses y ámbitos musicales resulta de vital importancia para avanzar en la incorporación de las tecnologías digitales en la educación musical.

Competencia 1. Desarrollo de contenidos digitales

\begin{tabular}{|l|l|l|}
\hline A- Básico & B - Intermedio & C - Avanzado \\
\hline Busca, crea, almacena y edita & Crea contenidos digitales en & Crea materiales digitales \\
sencillos contenidos digitales & diferentes formatos, como, & propios del aula de música \\
adecuados al área de educación & por ejemplo, backing tracks, & en línea en una amplia gama \\
musical. & de formatos y los publica en \\
& promueve la creación de este & espacios digitales muy variados \\
& tblog, página web, etc.). \\
& alumnado de música. & \\
\hline
\end{tabular}


Competencia 2. Integración y reelaboración de contenidos digitales

\begin{tabular}{|c|c|c|}
\hline A- Básico & B - Intermedio & C - Avanzado \\
\hline $\begin{array}{l}\text { Es consciente de que Internet } \\
\text { es una inacabable fuente de } \\
\text { recursos musicales que puede } \\
\text { reutilizar y realiza modificaciones } \\
\text { sencillas con fines educativos. }\end{array}$ & $\begin{array}{l}\text { Es conocedor y usuario de } \\
\text { repositorios de recursos } \\
\text { educativo musicales. Modifica } \\
\text { y adapta recursos tanto propios } \\
\text { como ajenos para adaptarlos a } \\
\text { su alumnado. }\end{array}$ & $\begin{array}{l}\text { Diseña materiales y actividades } \\
\text { digitales para el área de } \\
\text { educación musical a partir de } \\
\text { la yuxtaposición o remezcla } \\
\text { de recursos procedentes de } \\
\text { distintos espacios, tanto propios } \\
\text { como ajenos. }\end{array}$ \\
\hline
\end{tabular}

Competencia 3. Derechos de autor y licencias

\begin{tabular}{|c|c|c|}
\hline A- Básico & B - Intermedio & C - Avanzado \\
\hline $\begin{array}{l}\text { Es consciente de que algunos } \\
\text { contenidos distribuidos en } \\
\text { Internet y que pueden usarse } \\
\text { en el aula de música tienen } \\
\text { derechos de autor y los respeta. }\end{array}$ & $\begin{array}{l}\text { Conoce las diferencias básicas } \\
\text { entre licencias abiertas y } \\
\text { privativas y cómo estas afectan } \\
\text { a los contenidos digitales } \\
\text { adecuados para la educación } \\
\text { musical. Promueve entre su } \\
\text { alumnado conciencia hacia el } \\
\text { respeto de los derechos de autor } \\
\text { de contenidos digitales. }\end{array}$ & $\begin{array}{l}\text { Conoce cómo se aplican los } \\
\text { diferentes tipos de licencias a } \\
\text { la información y a los recursos } \\
\text { digitales destinados a la } \\
\text { educación musical que usa y } \\
\text { que crea. Desarrolla proyectos } \\
\text { educativos musicales para que } \\
\text { su alumnado publique en la } \\
\text { red contenidos con licencias de } \\
\text { acceso abierto. }\end{array}$ \\
\hline \multicolumn{3}{|l|}{ Competencia 4. Programación } \\
\hline A- Básico & B - Intermedio & C - Avanzado \\
\hline $\begin{array}{l}\text { Conoce los conceptos y } \\
\text { fundamentos básicos de la } \\
\text { informática y la tecnología } \\
\text { móvil en la educación musical. } \\
\text { Modifica la configuración de } \\
\text { algunas funciones básicas de } \\
\text { software y de aplicaciones } \\
\text { musicales. }\end{array}$ & $\begin{array}{l}\text { Modifica software y aplicaciones } \\
\text { de programación informática } \\
\text { musical para adaptarlas a las } \\
\text { necesidades de su alumnado en } \\
\text { lo que respecta al pensamiento } \\
\text { computacional. }\end{array}$ & $\begin{array}{l}\text { Tiene conocimiento avanzado } \\
\text { de los fundamentos de } \\
\text { programación y modifica } \\
\text { programas musicales de código } \\
\text { abierto. Desarrolla proyectos } \\
\text { para que su alumnado elabore } \\
\text { o modifique aplicaciones } \\
\text { musicales o cree juegos } \\
\text { destinados al aprendizaje de la } \\
\text { música. }\end{array}$ \\
\hline
\end{tabular}

Tabla 3. Niveles del área 3. Creación de contenido digital. Fuente propia adaptado de INTEF (2017).

Área 4. Seguridad: protección personal como docente de música, protección de datos y protección de la identidad digital; uso seguro y sostenible referido al área de la educación musical.

Competencia 1. Protección de dispositivos. Proteger los contenidos digitales y los dispositivos propios que se usan tanto en la preparación de las clases como en el aula de música (secuenciadores, editores, ordenadores, etc.); entender los riesgos y amenazas en red y conocer medidas de protección y seguridad.

Competencia 2. Protección de datos personales e identidad digital. Comprender el vocabulario habitual de uso de los programas y servicios digitales destinados a la educación musical (adiestradores auditivos, procesadores de audio, etc.); proteger activamente los datos personales como docente de música; respetar la privacidad del resto de profesorado y alumnado; protegerse a sí mismo de amenazas, fraudes y ciberacoso.

Competencia 3. Protección de la salud. Evitar riesgos para la salud relacionados con el uso de la tecnología musical en cuanto a amenazas para el bienestar psicológico y la integridad física.

Competencia 4. Protección del entorno. Tener en cuenta el impacto de las tecnologías 
digitales destinadas a la educación musical sobre el medio ambiente.

En el ámbito de la música, lamentablemente, nos encontramos ante demasiado software de libre acceso que esconde peligros para nuestros sistemas e instrumentos electrónicos. Una mala elección o no estar protegido ante esto puede, por ejemplo, provocar una desconfiguración irreparable de un teclado electrónico. Además, y en el aspecto personal, las posturas forzadas a las que está sometido un músico con su instrumento se pueden ver multiplicadas si además está frente a una pantalla de ordenador preparando un material didáctico concreto.

\begin{tabular}{|c|c|c|}
\hline A- Básico & B - Intermedio & C - Avanzado \\
\hline $\begin{array}{l}\text { Realiza acciones básicas de } \\
\text { protección de los distintos } \\
\text { dispositivos digitales y contenidos } \\
\text { propios guardados que utiliza } \\
\text { tanto en la preparación de las } \\
\text { clases como en el aula de música } \\
\text { (contraseñas, antivirus, etc.). }\end{array}$ & $\begin{array}{l}\text { Busca, actualiza y gestiona } \\
\text { adecuadamente sus } \\
\text { conocimientos sobre los peligros } \\
\text { digitales de sus dispositivos } \\
\text { usados en su práctica docente } \\
\text { musical. }\end{array}$ & $\begin{array}{l}\text { Examina y actualiza sus } \\
\text { dispositivos digitales usados } \\
\text { en su práctica docente para } \\
\text { identificar vulnerabilidades } \\
\text { o fallos de funcionamiento y } \\
\text { buscar las soluciones adecuadas. }\end{array}$ \\
\hline \multicolumn{3}{|c|}{ Competencia 2. Protección de datos personales e identidad digital } \\
\hline A- Básico & B - Intermedio & C - Avanzado \\
\hline $\begin{array}{l}\text { Es consciente de que en entornos } \\
\text { en línea puede compartir sólo } \\
\text { ciertos tipos de información } \\
\text { sobre sí mismo como docente y } \\
\text { sobre otros (tanto colegas como } \\
\text { alumnos de música). }\end{array}$ & $\begin{array}{l}\text { Conoce cómo proteger su propia } \\
\text { privacidad en línea como docente } \\
\text { y la de los demás (tanto colegas } \\
\text { como alumnos), realizando } \\
\text { actividades didácticas para } \\
\text { concienciar en este sentido. }\end{array}$ & $\begin{array}{l}\text { A menudo cambia la } \\
\text { configuración de privacidad } \\
\text { predeterminada de los servicios } \\
\text { en línea destinados a la } \\
\text { educación musical para mejorar } \\
\text { la protección de su privacidad. y } \\
\text { desarrolla proyectos educativos } \\
\text { destinados a formar al alumnado } \\
\text { de música en hábitos digitales } \\
\text { de protección y de respeto a la } \\
\text { privacidad de los demás. }\end{array}$ \\
\hline \multicolumn{3}{|l|}{ Competencia 3. Protección de la salud } \\
\hline A- Básico & B - Intermedio & C - Avanzado \\
\hline $\begin{array}{l}\text { Sabe que la tecnología digital } \\
\text { destinada a la educación musical } \\
\text { puede afectar a su salud si se } \\
\text { utiliza mal. }\end{array}$ & $\begin{array}{l}\text { Sabe cómo protegerse a sí } \\
\text { mismo y a otros del ciberacoso. } \\
\text { Entiende los riesgos para la } \\
\text { salud asociados al uso de } \\
\text { tecnologías digitales destinadas } \\
\text { a la educación musical (desde la } \\
\text { adicción a las tecnologías hasta } \\
\text { los aspectos ergonómicos). }\end{array}$ & $\begin{array}{l}\text { Conoce el uso adecuado de las } \\
\text { tecnologías digitales destinadas } \\
\text { a la educación musical para } \\
\text { evitar problemas de salud. } \\
\text { Conoce cómo encontrar el } \\
\text { equilibrio entre el mundo real y } \\
\text { el virtual. }\end{array}$ \\
\hline \multicolumn{3}{|l|}{ Competencia 4. Protección del entorno } \\
\hline A- Básico & B - Intermedio & C - Avanzado \\
\hline $\begin{array}{l}\text { Sabe cómo reducir el consumo } \\
\text { energético y conoce los problemas } \\
\text { medioambientales ocasionados } \\
\text { por la fabricación, uso y desecho } \\
\text { de los dispositivos digitales } \\
\text { destinados al área de educación } \\
\text { musical. }\end{array}$ & $\begin{array}{l}\text { Tiene opiniones informadas sobre } \\
\text { los aspectos positivos y negativos } \\
\text { del uso de la tecnología sobre el } \\
\text { medio ambiente y sabe optimizar } \\
\text { la utilización de los dispositivos } \\
\text { destinados a la educación } \\
\text { musical. }\end{array}$ & $\begin{array}{l}\text { Organiza estrategias eficientes } \\
\text { de uso de dispositivos digitales } \\
\text { y toma decisiones de compra } \\
\text { y desecho adecuadas en } \\
\text { consonancia con las actividades } \\
\text { educativo musicales que realiza } \\
\text { con ellos. }\end{array}$ \\
\hline
\end{tabular}

Tabla 4. Niveles del área 4. Seguridad. Fuente propia adaptado de INTEF (2017). 
Área 5. Resolución de problemas: identificar necesidades y recursos digitales aplicables a la educación musical; tomar decisiones a la hora de elegir la herramienta digital apropiada para la docencia musical acorde a la finalidad o necesidad; resolver problemas conceptuales a través de medios digitales.

Competencia 1. Resolución de problemas técnicos. Identificar posibles problemas técnicos en el software destinado a la educación musical y resolverlos (adiestradores vocales, editores de partituras, etc.).

Competencia 2. Identificación de necesidades y respuestas. Analizar las necesidades propias tanto de uso de recursos y herramientas como de desarrollo competencial, y realizar las posibles soluciones adaptando, si es necesario, las herramientas; evaluar de forma crítica las posibles soluciones y herramientas propuestas aplicables al área de Educación Musical.

Competencia 3. Innovación y uso de la tecnología digital de forma creativa. Innovar utilizando la tecnología digital aplicada a la educación musical; involucrarse y crear conocimiento a través de producciones colaborativas multimedia (arreglos orquestales, plickers educativos, etc.).

Competencia 4. Identificación de lagunas en la competencia digital. Comprender las necesidades propias y ajenas de mejora y actualización de la competencia digital docente referida a la educación musical y realizar acciones para mejorarla.

Esta área está referida a adoptar soluciones ante de la problemática al trabajar, por ejemplo, con un editor de partituras en casa y al exportar una partitura al sistema operativo del centro en el que se imparten clases, modificarse todos los sonidos, formatos, etc. Además, se trata de un área transversal que recoge de las anteriores al referirse a la búsqueda de adaptabilidad en cada uno de los recursos.

Competencia 1. Resolución de problemas técnicos

\begin{tabular}{|l|l|l|}
\hline A- Básico & B - Intermedio & C - Avanzado \\
\hline $\begin{array}{l}\text { Es conocedor de las características } \\
\text { de las herramientas, dispositivos } \\
\text { entornos y servicios digitales que } \\
\text { utiliza de forma habitual en su } \\
\text { docencia musical y es capaz de } \\
\text { identificar un problema técnico } \\
\text { explicando claramente en el } \\
\text { porqué de su mal funcionamiento. }\end{array}$ & $\begin{array}{l}\text { Puede resolver los problemas } \\
\text { técnicos no complejos } \\
\text { relacionados con entornos y } \\
\text { dispositivos digitales habituales } \\
\text { en su docencia musical con la } \\
\text { ayuda de información técnica. }\end{array}$ & $\begin{array}{l}\text { Tiene un conocimiento avanzado } \\
\text { de las características de las } \\
\text { herramientas, dispositivos } \\
\text { entornos y servicios digitales que } \\
\text { utiliza de forma habitual en su } \\
\text { docencia musical y puede resolver } \\
\text { y ayudar a resolver de forma } \\
\text { autónoma los posibles problemas } \\
\text { técnicos cuando surgen. Participa } \\
\text { en foros virtuales de discusión } \\
\text { ayudando a sus colegas en la } \\
\text { solución de posibles problemas } \\
\text { técnicos. }\end{array}$ \\
\hline $\begin{array}{l}\text { Competencia 2. Identificación de necesidades y respuestas tecnológicas } \\
\text { A- Básico }\end{array}$ & B - Intermedio \\
$\begin{array}{l}\text { Utiliza de forma crítica algunos } \\
\text { recursos digitales para atender } \\
\text { resolver problemas tecnológicos } \\
\text { relacionados con su trabajo como } \\
\text { docente de música. }\end{array}$ & $\begin{array}{l}\text { Evalúa con sentido crítico las } \\
\text { herramientas, dispositivos } \\
\text { entornos y servicios digitales } \\
\text { disponibles en la educación } \\
\text { musical y selecciona la solución } \\
\text { más adecuada en función de las } \\
\text { necesidades de cada momento. }\end{array}$ & $\begin{array}{l}\text { Toma decisiones razonadas al } \\
\text { elegir un dispositivo, herramienta, } \\
\text { aplicación, programa o servicio } \\
\text { nara una tarea docente con la que } \\
\text { actualizado sobre los nuevos } \\
\text { desarrollos tecnológicos. }\end{array}$ \\
\hline
\end{tabular}


Competencia 3. Innovación y uso de la tecnología digital de forma creativa

\begin{tabular}{|l|l|l|}
\hline A- Básico & B - Intermedio & C - Avanzado \\
\hline $\begin{array}{l}\text { Sabe que puede usar las } \\
\text { tecnologías digitales en su } \\
\text { docencia musical para buscar } \\
\text { soluciones innovadoras que } \\
\text { faciliten las tareas de aprendizaje. }\end{array}$ & $\begin{array}{l}\text { Utiliza las tecnologías digitales } \\
\text { para analizar necesidades en } \\
\text { su docencia musical, proponer, } \\
\text { crear y gestionar soluciones } \\
\text { innovadoras, y participar en } \\
\text { proyectos creativos aunque no } \\
\text { tome la iniciativa. }\end{array}$ & $\begin{array}{l}\text { Es conocedor de una amplia } \\
\text { gama de formas innovadoras de } \\
\text { utilizar las tecnologías digitales } \\
\text { aplicadas a su labor docente } \\
\text { en el ámbito de la música, y } \\
\text { se actualiza de acuerdo con } \\
\text { la evolución de los medios } \\
\text { digitales y las necesidades de } \\
\text { aprendizaje. Participa activamente } \\
\text { en comunidades de profesores de } \\
\text { música que comparten iniciativas } \\
\text { innovadoras de uso educativo de } \\
\text { los medios digitales. }\end{array}$ \\
\hline $\begin{array}{l}\text { Competencia 4. Identificación de lagunas en la competencia digital } \\
\text { A- Básico }\end{array}$ & B - Intermedio \\
\hline $\begin{array}{l}\text { Identifica las necesidades propias } \\
\text { pluso de medios digitales en el } \\
\text { proceso de enseñanza-aprendizaje. }\end{array}$ & $\begin{array}{l}\text { Busca y experimenta con } \\
\text { tecnologías digitales que le } \\
\text { ayudan a mantenerse actualizado } \\
\text { y a cubrir posibles lagunas en } \\
\text { la competencia digital necesaria } \\
\text { para su labor como profesor de } \\
\text { música. }\end{array}$ & $\begin{array}{l}\text { Octualización y aprendizaje, } \\
\text { realiza cambios y adaptaciones } \\
\text { metodológicas para la mejora } \\
\text { continua del uso educativo } \\
\text { musical de los medios digitales. } \\
\text { Comparte con sus colegas sus } \\
\text { avances y les apoya a en su } \\
\text { desarrollo competencial. }\end{array}$ \\
\hline
\end{tabular}

Tabla 5. Niveles del área 5. Resolución de problemas. Fuente propia adaptado de INTEF (2017).

\section{Conclusiones}

En conclusión, existe un marco desarrollado por el Instituto Nacional de Tecnologías Educativas y Formación del Profesorado (INTEF, 2017) que permite que cada docente pueda autoevaluarse y conocer así su perfil competencia en lo que al uso de la tecnología educativa se refiere. Si bien este es común, el área de didáctica de la música presenta una serie de singularidades y vocabulario específico que aquí se ha incluido en la propuesta del INTEF. Como herramienta de autoevaluación, puede servir a los docentes para conocer sus carencias y los aspectos a mejorar y así estar en consonancia con el alumnado de hoy en día.

Esta autoevaluación puede suponer un revulsivo al hacer consciente a cada docente de sus lagunas personales o incluso carencias como colectivo y poder buscar remedios. Por tanto, la adaptación que aquí se ha mostrado, puede suponer también un referente a la hora de definir acciones concretas entre el profesorado de música en pro de su Competencia Digital Docente. Además, dichas acciones pueden significar un factor de innovación educativa y base para investigaciones en esta línea.

De esta forma se puede avanzar en la educación musical, incorporando las tecnologías digitales como recurso educativo. En este sentido cada profesor ha de conocer además las especificidades de su propia docencia. Por ejemplo un maestro de primaria necesitará más desarrollar la creación de musicogramas mientras que un profesor de escuela de música o conservatorio debería 
incidir en el uso de editores de partituras.

Ahora ya "solo" es nuestra labor enfrentarnos a nuestras carencias.

\section{Referencias bibliográficas}

Bauman, Z. (2005). Los retos de la educación en la modernidad líquida. Barcelona: Gedisa.

Belletich, O., Angel-Alvarado, R., y Wilhelmi, M. R. (2017). Epistemic norms in the musical training for primary teacher education. Journal for Educators, Teachers and Trainers, 8(1), 199-213. Recuperado de http://www.ugr.es/ jett/index.php

Calderón-Garrido, D. (2013). La práctica musical en grupo como camino hacia el bienestar de los adolescentes. En J. Gustems (Coord.), Arte y bienestar (pp. 75-83). Barcelona: Publicacions Universitat de Barcelona.

Carrera, F. X., y Coiduras, J. L. (2012). Identificación de la competencia digital del profesor universitario: un estudio exploratorio en el ámbito de las Ciencias Sociales. Revista Docencia Universitaria, 10(2), 273-298. Recuperado de http://hdl.handle.net/10459.1/47980

Comisión Europea (2016). Education and training. Monitor 2016. Recuperado de https://ec.europa. eu/education/sites/education/files/monitor2016-pt_en.pdf

Ferrari, A. (2013). DIGCOMP: A Framework for Developing and Understanding Digital Competence in Europe. Sevilla: European Commission. Joint Research Centre. Institute for Prospective Technological Studies.

Fullan, M., y Donelly, K. (2013). Alive in the Swamp: assessing digital innovations in education. Londres: Nesta.

Generalitat de Catalunya (2018). Teachers' digital competence in Catalonia. Barcelona: Servei de Comunicació i Publicacions.

INTEF (2017). Marco Común de Competencia Digital Docente. Madrid: Ministerio de Educación, Ciencia y Deportes.

Parlamento Europeo y del Consejo (2006). Recomendación del Parlamento Europeo y del Consejo de 18 de diciembre de 2006 sobre las competencias clave para el aprendizaje permanente. Diario Oficial de la Unión Europea.

Redecker, C. (2017). European Framework for the Digital Competence of Educators. DiGiCompEdu. Luxemburgo: Publications Office of the European Union.

Tourón, J., Martín, D., Navarro, E., e Iñigo, V. (2018). Validación de constructo de un instrumento para medir la competencia digital docente de los profesores (CDD). REP. Revista Española de Pedagogía, 76(269), 25-54. doi: 10.22550/REP76-1-2018-02

UNESCO (2002). Information and communication technology. A curriculum for schools and programme of teacher development. Paris: UNESCO. 